\title{
Shared Communication in Building Mathematical Ideas: A Longitudinal Study
}

\begin{abstract}
Students make sense of mathematical ideas using a variety of representations including physical models, pictures, diagrams, spoken words, and mathematical symbols. As students' understanding of mathematical ideas becomes more general and abstract, there is a need to express these ideas using mathematical notation. This paper describes students' movement from model building and personal notations to elegant use of mathematical symbols that show their understanding of advanced counting ideas. Specifically, this paper shows how earlier ideas from investigations of specific combinatorics problems (questions about making pizzas with different toppings and using cubes to build towers) are retrieved and built upon using the formal mathematical register to explain the meaning of Pascal's Identity, the addition rule of Pascal's Triangle. This analysis also shows the power of shared communication in mathematical problem solving.
\end{abstract}

\subsection{Introduction}

The mathematical register can be described as the language of mathematics that is used to express mathematical ideas (Halliday, 1978). In this work I trace, over an eight-year period, the developing use of the mathematical register of a group of students who were participants in a long-term study of the development of mathematical ideas and ways of reasoning (Maher, 2005, 2010; Muter, 1999). I focus on student work on problem tasks in counting and combinatorics beginning in the elementary grades and continuing through middle school and high school. By high school, the students demonstrated understanding of the structure of the solutions to several problems in combinatorics. They related what they understood to representations of Pascal's Triangle. Finding their personal notations inadequate for the challenge of generalizing their findings, the students made use of standard mathematical notation to represent Pascal's Identity.

\subsection{Objectives}

There are two objectives in this paper: (1) to show how the students' ways of communicating about and representing their thinking evolved from idiosyncratic and personal to general and shared; (2) to trace how their focus moved from surface features of attributes of the tasks to the mathematical structure shared by both tasks. In particular, this paper describes how the students came to represent Pascal's Identity using standard notation for combinations.

In addition to tracing the evolution of personal notation to formal representation, the analysis shows how the students communicated their understandings to each other and to other observers using standard mathematical terminology. In the students' journey from use of personal notations to use of the mathematical register, they combined their understanding of the specific combinatorics problems with their knowledge of standard mathematical notation in order to express Pascal's Identity; in that way, they displayed their understanding of the structure of the general solution. 


\section{Shared Communication in Building Mathematical Ideas: A Longitudinal Study}

\subsection{Overview}

The paper is organized into seven sections.

- The introduction provides the setting for the research.

- The second section provides the theoretical framework guiding the analyses; this includes shared communication among learners and how their personal notations developed over time as they built mastery of the mathematical register.

- The methodology section describes data collection, analyses, and procedures; this section also provides a detailed description of the mathematical problems that form the focus of this study (the towers and pizza problems).

- The results sections traces how the students dealt with the towers and pizza problems and how, over time, they discovered the isomorphic relationship between the pizza and towers problems and the isomorphic relationship between each of these problems and other mathematical entities (e.g. the binomial expansion).

- The discussion section summarizes the results.

- The sixth section discusses pedagogical implications.

- The concluding section discusses implications for practice.

\section{Theoretical Framework}

The framework that guides this analysis relates to communication among learners of mathematics and representations used by learners of mathematics. The importance of communication among learners has been documented extensively (e.g. Sfard, 2000; Maher, 2005; Morgan, 2006; Staats \& Batteen, 2010). Research shows that students can and should use personal notations when exploring new mathematical ideas (Maher \& Martino, 1999; Maher, Sran, \& Yankelewitz, 2010a). However, students are expected eventually to master the standard mathematical register in order to generalize and communicate their mathematical ideas (National Council of Teachers of Mathematics, 2000; O'Halloran, 1987; Skemp, 1978).

\subsection{Representations and the Mathematical Register}

As noted by Cuoco, the idea of representations can be difficult to define precisely:

All of us have an intuitive idea of what it means to represent a situation; we do it all the time when we teach or do mathematics. ... But what do we mean, precisely, by "representation," and what does it mean to represent something? These turn out to be hard philosophical questions that get at the very nature of mathematical thinking. (Cuoco, 2001, p. x)

In fact, in many instances, the meaning of "representation" is left undefined. For example, the Common Core State Standards for mathematics (CCSS, 2010) discuss the use of representations and require that students use and make sense of various representations but the term "representation" is never defined. In this paper, I focus on external representations (those that are observable) and I define them by way of example. 


\section{Shared Communication in Building Mathematical Ideas: A Longitudinal Study}

Pictures, models, words, and symbols are representations that will be discussed in this paper. In addition, students' personal representations - models, words, pictures, and symbols developed by students - will be contrasted with the type of representation called the standard mathematical register.

The mathematical register can be considered the language of mathematics used to express mathematical ideas. Since Halliday's early work (1978), other researchers have expanded on this definition. For example, Pimm (1987) states that the language of mathematics is characterized by its use of specialized words and phrases and of the use of everyday words with specialized meanings. In addition, O'Halloran (2005) lists three semiotic components of the mathematical register as "language, visual images and mathematical symbolism" (p. 11). However, there is no clear distinction between the mathematical register and regular language that is not part of mathematical discourse (Moschkovich, 2008; Barwell, 2013). Further, Barwell notes, "Everyday language does not disappear in mathematics; it is used in new, more mathematical ways" (p. 221). For purposes of this analysis, I follow O'Halloran, considering the mathematical register to be composed of images, mathematical symbols, and spoken or written language. I consider use of language to include use of specialized mathematical terms, use of everyday words with specialized mathematical meanings, and, following Barwell, ordinary language used in mathematical ways.

Proficiency in the mathematical register aligns with the CCSS goal that students should "attend to precision" (2010, p. 7) in their communication about mathematics.

Furthermore, proficiency with the mathematical register enables students to achieve the CCSS requirement that high school students be able to "make explicit use of definitions" (p. 7). However, Barwell (2013) observes that students do not progress linearly from everyday language to formal use of the mathematical register; moreover, there is a place in mathematical discourse for everyday language. Students should not just learn to use the mathematical register; they should be "able to express mathematics for a range of different audiences" (Barwell, p. 220). In this study, I show how these students did learn to use different language depending on the situation.

\subsection{Personal Notations}

Studying students' representations is important because of the importance of representations in mathematics. Hoffman (2006) asserts, "the essence of mathematics consists in working with representations" (p. 279). Additionally, studying students' representations is a way to determine their level of mathematical understanding (Goldin, 1998; Sfard, 2000).

It is helpful for students to develop their own personal notations when they are learning mathematics. The National Council of Teachers of Mathematics (NCTM, 2000) recommends that before students learn standard notation, they should first have the opportunity to construct their own representations. According to Davis and Maher (1997), students who are provided with varied mathematical experiences build repertoires 


\section{Shared Communication in Building Mathematical Ideas: A Longitudinal Study}

of representations, which they can use to deal with new mathematical ideas. When students revisit problems, they refine their representations (Muter \& Maher, 1999).

Nevertheless, personal representations alone are often inadequate for dealing with mathematical situations. Students must eventually master standard mathematical symbolism and be able to use standard notation communicate their ideas. For example, the NCTM (2000) states that, although students should be able to use personal notations when developing mathematical ideas, teachers should introduce students to standard notations, possibly by building on the students' personal notations (p. 362). Standard notations provide a common language for communicating mathematically; they can also help students extract the important features of a mathematical problem, by highlighting what is significant as opposed to what is superficial (Lehrer, Schauble, Carpenter, \& Penner, 2000). Schleppegrell notes that students must learn to "move between everyday, informal ways of constructing knowledge and the technical and academic ways that are necessary for advanced learning” (2007, p. 79). Similarly, Skemp (1987) observes that students may be ready to communicate using the standard mathematical register when they find their personal notations to be inadequate:

These ways of expression [personal notations] may often be lengthy, unclear, and differ between individuals. By experience of these disadvantages, and by discussion, children may gradually be led to the use of established mathematical symbolism in such a way that they experience its convenience and power for communicating and manipulating mathematical ideas. (p. 183)

Students also need to be able to communicate their thoughts using standard mathematical notations in assessment situations, such as the standardized tests mandated by law. In particular, the Common Core State Standards (CCSS, 2010) specify that students should use the tools of mathematics appropriately; these tools include mathematical symbolism and mathematical language. I demonstrate below that guiding students to the use of precise language and showing them the importance of being able to provide cogent justification for their answers can help provide them with the tools required by the Common Core State Standards.

\subsection{Communication}

Communication about mathematics is considered to be a crucial component of learning mathematics. For example, Schleppegrell writes: "The notion of mathematics as discourse and students as being apprenticed into particular ways of doing mathematics in particular discursive contexts are now gaining prominence in mathematics education research" (2007, p. 74). Morgan (2006) indicates that "meaning making occurs in social contexts" (p. 220). Staats and Batteen (2010) state, "students build knowledge collaboratively by listening and reacting to each other's ideas" (p. 45). This study shows how discourse - communicating within a social context, including discourse among students and discourse between students and researchers - was crucial as the group built mathematical ideas and developed fluency in the use of the mathematical register. 


\section{Shared Communication in Building Mathematical Ideas: A Longitudinal Study}

\subsection{Research Questions}

The questions that guide this study are:

1. What representations did the students use to communicate their ideas about and solutions to the combinatorics tasks?

2. How did they move from use of earlier representations to use of the mathematical register?

\section{Methodology}

\subsection{Participants}

Ankur, Brian, Jeff, Michael, and Romina were among the original participants in a longitudinal study of children's learning of mathematics. This study followed a group of students from the Kenilworth, NJ public schools from first grade through college (Maher, 1998; Maher \& Martino, 1999; Maher, 2002; Maher, 2010). The group originally consisted of 18 first-graders; other students later joined the study. At first, researchers met with students in the classroom approximately four times a year, for two to three days at a time, in sessions lasting from one to three hours. When the students were in the last three years of high school, the meetings (again one to three hours long) took place after school, also about four times a year. Over the years of this longitudinal study, students were presented with open-ended challenging problems, many dealing with combinatorics. The purpose of the longitudinal study was not to teach the students particular topics in mathematics but to establish a culture where the correctness of an answer came from the sense-making of the students, rather than from the authority of the researcher. Students' justifications for their reasoning were triggered by researcher questions about what was convincing, what made sense, and how students developed their answers. Moreover, students were not originally shown the standard notations of combinatorics; they used whatever representations they and their classmates created.

\subsection{Mathematical Context}

The students worked on topics in algebra, geometry, combinatorics, probability, precalculus, and calculus. This study focuses on their work on two particular problems in combinatorics, the pizza and towers tasks, and their relation to Pascal's Triangle (Maher, Powell \& Uptegrove, 2010). Further details on these aspects of the longitudinal study can be found in Maher, Sran, and Yankelewitz (2010b), Muter and Uptegrove (2010), and Uptegrove $(2005,2007,2010)$. 


\section{Shared Communication in Building Mathematical Ideas: A Longitudinal Study}

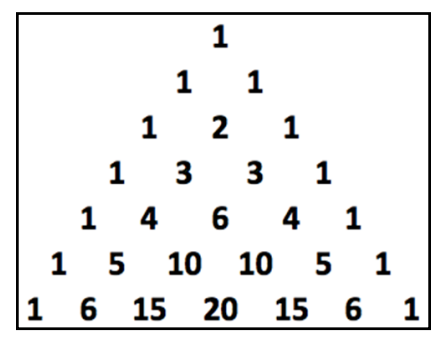

Figure 1. Pascal's Triangle (rows 0 through 6)

For reference, rows 0 through 6 of Pascal's Triangle are shown in Figure 1. The pizza and towers problems are:

1. Pizza: How many unique pizzas is it possible to make when there are $n$ toppings to choose from, and each topping is placed on the whole pizza? Answer: each of the $n$ toppings can be on or off the pizza; therefore, there are $2^{n}$ possible pizzas.

2. Towers: How many towers $n$ cubes tall can be built when building towers and selecting from two different colors (for example red and yellow) of Unifix cubes? Answer: each position in the tower can be filled with either a red cube or a yellow cube; therefore there are $2^{n}$ possible towers. [Note: Unifix cubes are interlocking cubes that are sold as educational supplies. They come in ten colors and they can be attached in one direction; i.e. each cube has a top and a bottom.]

These problems are mathematically isomorphic; that is, they have the same mathematical structure, although the problems have different surface features. One way to express the isomorphism uses $C(n, r)$, the notation for the $r^{\text {th }}$ entry in the $n^{\text {th }}$ row of Pascal's Triangle:

1. If $n$ is the number of choices for pizza toppings and $r$ is the number of toppings present on a given pizza, then $C(n, r)$ represents the number of pizzas with exactly $r$ toppings when there are $n$ choices for pizza toppings.

2. If $n$ is the height of a tower and $r$ is the number of yellow cubes in a given tower, then $C(n, r)$ represents the number of towers of height $n$ with exactly $r$ yellow cubes when choosing from red and yellow cubes to build towers.

In other words, the number of available pizza toppings can be mapped to the height of the tower $(n)$ and the number of pizzas with exactly $r$ toppings when there are $n$ available toppings can be mapped to the number of towers of height $n$ with exactly $r$ cubes of a particular color when there are two colors to choose from. Furthermore, a particular position in the tower can be mapped to a particular pizza topping, with a cube of one color indicating that the associated topping is on the pizza and a cube of the other color indicating that the associated topping is not on the pizza. In this manner, each tower can be mapped to a particular pizza. Figure 2 shows specific examples of the relationship 


\section{Shared Communication in Building Mathematical Ideas: A Longitudinal Study}

between the eight three-tall towers and the eight possible pizzas with available toppings peppers, sausage, and mushrooms. Suppose a yellow cube indicates that the associated topping is present and a red cube indicates that the topping is not present. Then, the RedRed-Red tower maps to the plain pizza, and the Yellow-Yellow-Yellow tower maps to the pizza with all three toppings, for example.

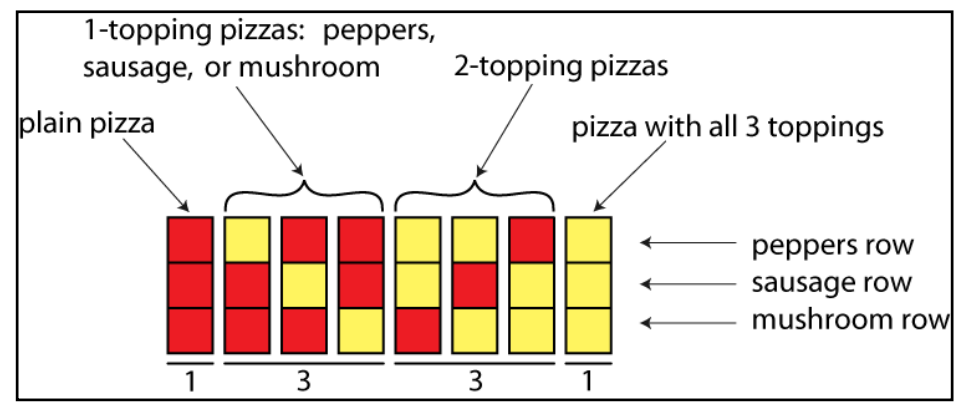

Figure 2. An illustration of the isomorphism between pizzas and towers

The additive rule for generating entries in Pascal's Triangle (Pascal's Identity) can be expressed in the notation of combinatorics in several ways. Two are given in Figure 3.

$$
C(n, r)=C(n-1, r)+C(n-1, r-1) \text { or }\left(\begin{array}{c}
n \\
r
\end{array}\right)=\left(\begin{array}{c}
n-1 \\
r
\end{array}\right)+\left(\begin{array}{c}
n-1 \\
r-1
\end{array}\right) \text {, for } 1 \leq r \leq n
$$

Figure 3. Pascal's Identity in two versions of combinatorial notation

Pascal's Identity can also be expressed using factorial notation, as shown in Figure 4.

$$
\frac{n !}{r !(n-r) !}=\frac{(n-1) !}{r !(n-1-r) !}+\frac{(n-1) !}{(r-1) !(n-r) !}, \text { for } 1 \leq r \leq n
$$

Figure 4. Pascal's Identity (factorial form)

Individual instances of Pascal's Identity can be expressed in terms of solutions to the towers or pizza problems. For example, consider the set of three-tall towers, as shown in Figure 2 above, represented by the numbers 1331 in row 3 of Pascal's Triangle.

According to Pascal's Identity, add 1 to 3 in order to obtain the first 4 in row 4 by the following procedure: Place a yellow cube on the one tower that has no yellow cubes and place a red cube on the three towers that already have one yellow cube. In this manner, build the four-tall towers that have exactly one yellow cube. This is shown in Figure 5. 


\section{Shared Communication in Building Mathematical Ideas: A Longitudinal Study}

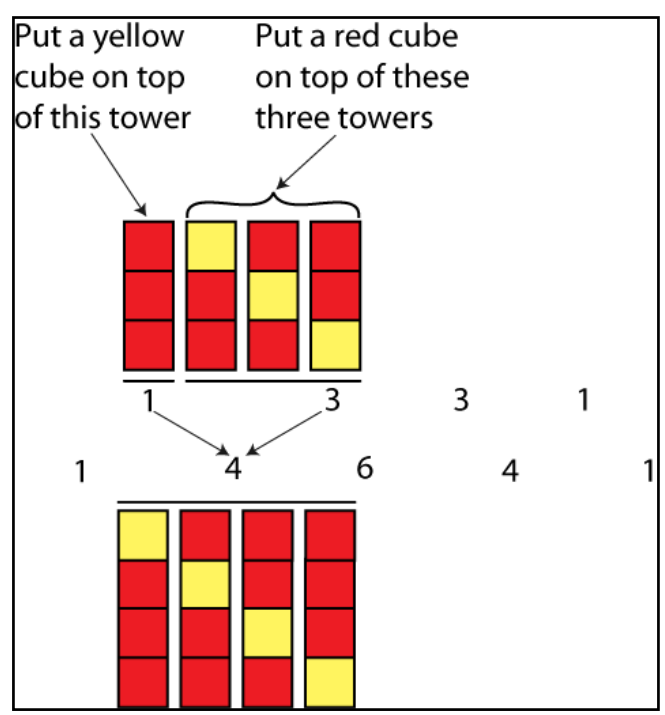

Figure 5. Using towers to illustrate an instance of Pascal's Identity

\subsection{Data Source}

Data are from archived student work from the longitudinal study described above in Section 3.1. They consist of videos and verified transcripts, student written work, and researcher notes from grades 3, 4, 5, 10, and 11. Many of these videos are available on the Video Mosaic Repository (VMC), an open-source web site (http://videomosaic.org/) that provides videos of students building mathematical ideas as they work on challenging mathematical tasks (Maher, Landis \& Palius, 2010).

As noted above, elementary grade sessions took place during regular class time; highschool sessions took place after school. Sessions were selected for analysis if they included work on the pizza or towers problem by the five students in the cohort of interest (Ankur, Brian, Jeff, Michael, and Romina).

\subsection{Analysis}

The procedure for analysis involved the following sequence (Maher \& Martino, 1996; Powell, Francisco \& Maher, 2010).

1. Viewing the videos, verifying the transcripts, and viewing student work.

2. Identifying and coding discourse and representations related to the mathematical register (as described in the paragraph that follows).

3. Identifying connections between students' facility with the mathematical register and students' demonstration of mathematical competence.

In order to investigate the students' use and understanding of personal representations and standard notation and their movement from personal representations to use of the standard mathematical register, instances of the following codes were noted: 


\section{Shared Communication in Building Mathematical Ideas: A Longitudinal Study}

1. Discourse used to communicate about mathematical ideas, such as ordinary language with specialized mathematical meanings.

2. Representations, personal and shared, such as drawings, images, and symbols.

3. Use of the formal mathematical register, for example the standard notation for combinatorics.

Links that students made between personal representations and standard notations were also noted, along with evidence that students made sense of and were able to solve mathematical problems.

The analysis used data collected from five different years over a nine-year period. It began with the students' first investigation of the towers problem in third grade (one episode), continued through their additional investigations of towers problems in fourth grade (six episodes), and then progressed through their work on various versions of the pizza problem in fifth grade (five episodes). The analysis concluded with the students' work in their sophomore year (four episodes) and junior year of high school (one episode), when they revisited both problems and made the associations that enabled them to generate Pascal's Identity.

\section{Results and Discussion}

Over the years, the representations used by these student progressed from the use of personal representations - those created by individual students or groups of students that often focused on surface features of the problems and that were not amenable to generalizations - to use of the mathematical register - regular symbolic mathematical notation, with a focus on mathematical structure.

Early personal representations focusing on surface features included realistic depictions of pizzas. Later, as understanding of the problem task evolved, the students used more generalized representations that still retained some aspect of the surface features of the problems (letter codes for pizza toppings, for example). By high school, these students were using standard notation suitable for expressing complicated mathematical relationships and capable of expressing generalized mathematical ideas independent of surface features of individual problems (for example, particular colors of cubes or particular pizza toppings). An important aspect of their move to standard notation was the development of shared understandings. As individual students' ideas were adopted and elaborated by other students in the group, shared understandings emerged. These understandings served as a bridge between earlier, personal notations and the notations adopted by the group, and they led ultimately to the appropriate use of the notations of the mathematical register.

Sections 4.1 addresses the problem solving during the students elementary and middleschool years, when they worked on tower problems in grade three (3-tall towers) and grade four (4-tall and 5-tall), and a strand of pizza problems during grade 5. During these years, they identified patterns and developed organizational strategies. Section 4.2 reports on their work five years later, as secondary-school students. This section describes their use of more sophisticated notations, their recognition of the relationship between Pascal's 


\section{Shared Communication in Building Mathematical Ideas: A Longitudinal Study}

Triangle and the pizza and towers problems, their discovery of the isomorphic relationship between the problems, and their understanding of Pascal's Identity.

\subsection{Elementary and Middle School}

Ankur, Brian, Jeff, Michael, and Romina first worked on versions of the towers and pizza problems in elementary school, during grades 3 and 4. Early representations were concrete or pictorial, and they focused on surface features. For example, in order to answer the question of how many four-tall towers can be built selecting from two colors of Unifix cubes, the students' initial strategy was to build those towers in random order. For the pizza problem, students' initial representations were drawings of pizzas. The episodes that illustrate their representations and their ways of thinking about the problems are discussed here.

\subsubsection{Third Grade: Preliminary Work on the Three- and Four-Tall Tower Problem}

The first encounter with the towers problem took place when the students were in third grade. The four-tall towers problem presented to third graders was:

Your group has two colors of Unifix cubes. Work together and make as many towers of four cubes as you can using one or both colors of cubes. See if you and your partner can plan a good way to find all the towers.

In third grade, many students had no initial organizational strategy. However a few organized towers by pairs generally called "opposites." (The opposite of a tower had the same structure with the opposite color in each position; for example, the opposite of redred-red-yellow is yellow-yellow-yellow-red.) Once the concept of "opposite" was developed by some students, the idea was adopted by others; eventually, all the students shared the language of "opposite" tower. The word "opposite" as used by these students is not a standard mathematical term, but it had a shared meaning to the students who used it. In third grade, students used no written representations; the physical models of the towers served as concrete representations of the answer. Many of the third-grade students found 16 four-tall towers, even without an organizational strategy.

After working on the four-tall towers problem, students were asked to think about the three-tall towers problem. Most students predicted that they would be able to build more than 16 three-tall towers. Brian and Jeff, who worked together on this task, also indicated at first that there would be more three-tall towers, because removing cubes from four-tall towers would give them more cubes to build with. However, when they built the towers, they realized that there were only eight, because removing cubes to turn four-tall towers into three-tall towers created eight duplicate towers. The transcript of their discussion follows. Note that Jeff expressed a mathematical insight related to the doubling pattern that was later recognized by these students as fourth-graders.

Researcher: And you two think it was less also? Why do you think so? 


\section{Shared Communication in Building Mathematical Ideas: A Longitudinal Study}

Brian: $\quad$ Because you take one off the bottom and one off the top, you might have another that is the same as that. ... you can't use them because it's a match and they have to be different.

Researcher: And Brian, how did you figure that? [Note that Jeff answers, not Brian.] Jeff: $\quad$ Well, because, first of all, you could choose to do it the math problem. Sixteen minus eight is eight.

Researcher: You mean there is something about math to it?

Jeff: $\quad$ Yeah, because sixteen minus eight or eight plus eight equals sixteen. And when you take one away from each, it would be one minus, one minus, one minus, because it's sixteen minus eight or eight plus eight.

Brian and Jeff noticed that when a cube is removed from each of the 16 four-tall towers, it results in two copies of each of eight three-tall towers. Brian's way of expressing this was not especially clear, although it might have been understandable to those familiar with the context. But Jeff used the mathematical register in an appropriate way for a third grader, using specialized mathematical terminology (minus and plus), and also noting the relationship between addition and subtraction: the fact that $16-8=8$ is related to $8+8=$ 16. In addition, he observed that subtracting one from 16 eight times is equivalent to $16-$ 8; this is an important mathematical insight for a third-grader! We see that Brian and Jeff, in third grade, had already been introduced to the mathematical register. They used mathematical terminology appropriate to the situation when communicating with the researcher.

\subsubsection{Fourth Grade: Early Organizational Strategies for Towers}

One year later, students encountered a more complex version, the five-tall tower problem. Although all five students in this study, along with most of their classmates, had worked on the four-tall and three-tall tower problems only one year earlier, there was no indication that they recalled their previous solution. The task was:

How many towers can be built five-high when selecting from cubes available in two colors? How can you be sure that you have found all possible towers with no duplicate towers included?

Note that for this activity, the students were asked to "be sure" that they had all possible towers and no duplicates. In addition to dealing with the requirement to justify their answer, students also found that organization was essential in order for them to build all 32 five-tall towers.

Most students started out with pairs of "opposites" (as they had done in third grade), and they checked for duplicate towers by physically holding each newly-built tower next to an existing tower. Some students make up idiosyncratic non-mathematical names for these activities. For example, consider the following excerpt of a discussion between a researcher and partners Brian and Romina, who called the comparison activity "taking them for a walk" and who named the opposite towers "couples" who are "married." 


\section{Shared Communication in Building Mathematical Ideas: A Longitudinal Study}

Researcher: What are you doing here?

Romina: Ah, we're making believe these are going for walks and couples...

Researcher: Going for walks and couples? OK. Wait, what are the requirements for being a couple?

Brian: Like, when you get, if you get like this, you just do the opposite. And then they're like married.

Researcher: So couples are like married? Couples are exact opposites?

Brian: $\quad$ Yeah....

Researcher: How do you know that none of these are the same? You said you take them for a walk?

Romina: Yeah. We take them for a stroll.

These personal representations do not generalize well and often do not work well as general communication tools, although they do show how students gave meaning to their problem solving and also enjoyed the opportunity for personal creativity. Yet this episode shows that even when using nonstandard terminology, the students noted that the "married couple" towers have an easily identifiable characteristic in common. Moreover, Brian and Romina followed a procedure (taking a tower "for a walk," i.e. comparing a newly-built tower to every other tower) that was guaranteed to identify duplicates. This can be considered an instance of what was described by Barwell (2013) as using everyday language in "new, more mathematical ways" (p. 221).

In this same session, some students began to organize their towers into cases, prompted by researcher questioning about whether they had found all possible towers and did not have any duplicates. In the following excerpt, Jeff and a researcher discussed how two of his organizational groupings accounted for two groups of towers - those with exactly one yellow cube and those with exactly one red cube. Figure 6 shows Jeff's two groups.

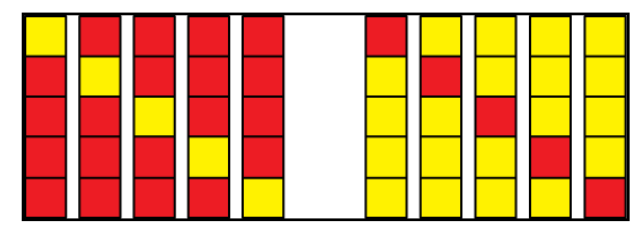

Figure 6. Two of Jeff's groups

Researcher: But how do I know you have all possible ones? Is there a way you can convince ... let's take this group [shown on the left side of Figure 6]. I'm convinced, that there are no more of these kind. Why do you think - what do you think convinces me?

Jeff: $\quad$ That they're, like, up in a row, there's like not any more. [Jeff pauses.]

Researcher: So ... I have a yellow here, or here, or here, or here, or here. One yellow's in any place you can have, right? I buy that, that's logical.

Jeff: $\quad$ And then, I found, gotta find these. Now. [Jeff pauses.]

Researcher: OK, let's take another set and try to convince me the same way.

Jeff: Well, I'll show you the other set. [This is the set on the right side of Figure 6.] 


\section{Shared Communication in Building Mathematical Ideas: A Longitudinal Study}

Researcher: Oh, OK. I believe this one too, you can have one red, right? And you have the other possibilities with one. I buy that.

Jeff could not be said to be using the mathematical register when he tried to explain why the groupings shown in Figure 6 provided a convincing argument. In indicating that there were no more towers with exactly one yellow cube because there were no other positions where the yellow cube could be, Jeff said, "they're, like, up in a row, there's like not any more." But the researcher reformulated what he said in a way that showed him a clearer way to express what he knew but had trouble saying ("One yellow's in any place you can have, right?")

In a session the following day, another researcher led a class discussion about how students organized their search and their findings. One partnership reported that, using the same pattern that Jeff had used, they had found five towers with exactly one blue cube. The researcher focused the students' attention on how they knew that there were only five such towers, by calling their attention to what she called the staircase pattern. A portion of the discussion follows.

Researcher: Everybody found the one that has a blue in the bottom? [Students answer yes.] OK, and then the next one in the staircase. Where's the blue there?

Students: Second.

Researcher: In the second one? And then?

Students: Third.

Researcher: And then?

Students: Fourth.

Researcher: And then?

Students: Fifth.

Researcher: Why can't there be any more? Why?

Student: 'Cause there's only five cubes in one tower.

Here is an instance of a researcher facilitating students' use of the mathematical register and encouraging students to justify their answers. After students were guided through all the possible positions for the blue cube and then asked why there were no more possible towers, the reason was "there's only five cubes in one tower." Contrast this language with Jeff's earlier statement ("there's like not any more"). The students were beginning to make use of the more precise language characterized by the mathematical register and required by the CCSS.

\subsubsection{Fourth grade: Finding a Pattern and Organizing by Cases}

In a later fourth grade tower investigation (investigating $n$-tall towers, where $n$ goes from 1 to 5), some students became aware of the doubling pattern: the fact that the number of $n$-tall towers is twice the number of (n-1)-tall towers. Jeff had been absent during some of these investigations, and in a follow-up interview between a researcher and Jeff and three classmates (Michelle, Milin, and Stephanie), he listened to his classmates explain their 


\section{Shared Communication in Building Mathematical Ideas: A Longitudinal Study}

work. First, Milin described the rule for building new towers, then Stephanie drew and explained her organization by cases, and finally Michelle connected Milin's and Stephanie's work by applying the doubling pattern to Stephanie's organized list.

\subsubsection{The Doubling Pattern}

This segment began after the students had recalled that the answer to the five-tall tower problem is 32 . When asked about six-tall towers, Milin gave the correct answer, but his explanation left Jeff confused.

Researcher: If you were building towers of six, how many would there be?

Jeff: $\quad$ I don't know....

Milin: $\quad$ Probably 64.

Researcher: Why do you think 64 ?

Milin: Well, because there was a pattern.

Researcher: What's that?

Milin: $\quad$ You just times them by two.

Researcher: Times what by two?

Milin: $\quad$ The towers by two, because one is two, and then we figured out two is two, and then, I mean four, and then -

Jeff: $\quad$ You are not making much sense!

Here, Milin indicates some knowledge of mathematical argumentation, in his reference to patterns. Also, note that meaning can be found in his explanation: "Times them [the towers] by two" meant that to get the number of possible towers of the next height, one would multiply the answer for the current height by two; this is why he predicted that the answer for six-tall towers would be 64 . When he said, "one is two," he was trying to express that there are two possible towers that are one cube tall; and "two is two ... I mean four" meant that there are four possible towers that are two cubes tall. Even though Milin might have understood this pattern, his communication of that understanding did not make good use of the mathematical register. "Times" in place of "multiply" is nonstandard but understandable, but statements such as "one is two" and "two is four" lack the attention to precise language called for in the CCSS. Milin's inability to provide a cogent explanation of what he knew made it difficult for Jeff to follow his argument.

\subsubsection{Organization by Cases}

Later in this session, Stephanie was challenged to support her assertion that there are exactly eight three-tall towers. She offered a form of proof by cases, partitioning the list of towers into groups with no blue cubes, exactly one blue cube, two blue cubes "stuck together," three blue cubes, and finally two blue cubes "separated." She drew the table shown in Figure 7 and explained her organization as follows: 


\section{Shared Communication in Building Mathematical Ideas: A Longitudinal Study}

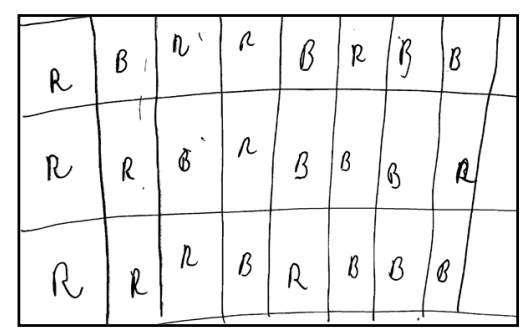

Figure 7. Stephanie's organized list of towers

Stephanie: All right, first you have without any blues, just red/red/red.

Researcher: OK, no blues.

Stephanie: Then you have with one blue: blue/red/red or $\mathrm{red} / \mathrm{blue} / \mathrm{red}$ or $\mathrm{red} / \mathrm{red} / \mathrm{blue}$.

Researcher: Anything else?

Stephanie: No, not with the blue, not with one blue. ... [Other students interrupt.]

Researcher: Let's see what Stephanie does.

Stephanie: Well, there's no more of these [towers with exactly one blue cube] because if you had to go down another one, you'd have to have another block on the bottom. [Note that this is a justification by contradiction.] Then you have with three blues. Well, not with three blues, I'll go like this.

Researcher: You have no blues and now you have exactly one blue.

Stephanie: Now you have exactly two blue. You could put blue/blue/red. You could put red/blue and blue.

Milin: $\quad$ You could do blue, red, and blue.

Stephanie: Yeah, but that's not what I'm doing. I'm doing it so that they're stuck together.

Researcher: OK.

Jeff: $\quad$ There should be one with - there could be one with one red and then you could break it up and then there's one with two reds and one with three reds. ... There's all reds and then there's three reds, two reds. There should be one with one red. And then you change it to blue.

This discussion illustrates students' use of the mathematical register and students' shared development of ideas through moderately precise communication. Stephanie's justification by contradiction ("if you had to go down another one, you'd have to have another block on the bottom") recalled the earlier class discussion justifying the assertion that there are five towers with exactly one blue cube when dealing with five-tall towers ("there's only five cubes in one tower"). It was also a fairly sophisticated mathematical argument, which was understood and accepted by the other students. In addition, Stephanie's precise use of the language when discussing the two-blue-cube case provided an opportunity for her classmates to challenge what she said. She said, "Now you have exactly two blue," but in fact she listed only two of the three towers that have exactly two blue cubes. When Milin named the tower that was missing, Stephanie clarified her organizational strategy, adding the information that this case included only two adjacent blue cubes. ("I'm doing it so that they're stuck together.") "Stuck together" can be 


\section{Shared Communication in Building Mathematical Ideas: A Longitudinal Study}

considered ordinary language used to communicate about mathematics. Moreover, it is clear from Jeff's participation in the discussion and his suggestion for an alternative to Stephanie's grouping that he built on Stephanie's organizational strategy. Jeff had not understood Milin's earlier argument, which lacked attention to precision, but he followed Stephanie's more precise formulation of her argument. It is also notable that Jeff (along with Michelle and Milin) proposed a different organization: combining the "stuck together" and "separated" case of a tower with exactly two blue cubes. This might be considered an indication of an esthetic appreciation of a more elegant proof that minimizes the number of cases.

\subsubsection{An Explanation of the Doubling Pattern}

Later in that session, Michelle explained why the doubling pattern worked, building on input from both Milin and Stephanie. She annotated Stephanie's diagram, as seen in Figure 8, to show that each three-tall tower could grow to two different four-tall towers, through the addition of one or the other color cube. Jeff finished the explanation, continuing the count to 16 , the answer for four-tall towers.

Michelle: You can add a red or a blue here [indicating red/red/red tower].

Researcher: Make a Y or something to show me.

Jeff: $\quad$ I understand because you can only -

Michelle: You can put two colors here [she writes a 2 over the first three-tall tower], two colors there [she writes another 2 over the second tower], two colors and keep on going.

Jeff: $\quad$ Yeah, you can keep on doing two colors for each one. And that's two, four, six, eight, ten, 12,14, 16. [Jeff points to each 2 in turn as he counts.]

Researcher: And that's towers of?

Jeff: $\quad$ Four.

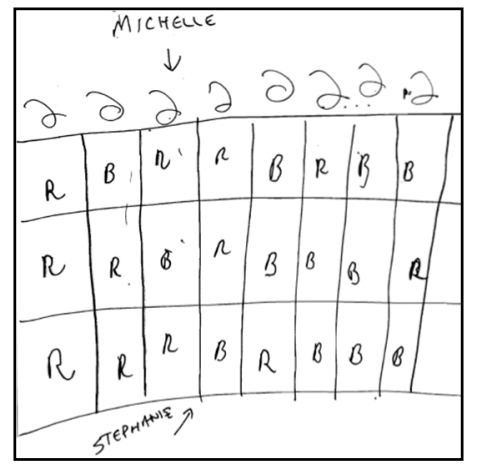

Figure 8. The doubling rule

Attention to precision is seen here in the organized way Michelle indicated that each tower would get the same treatment in order to form two new towers. Other elements of the mathematical register include the word "add" and the statement that there are "two colors for each one" [tower]. Notice that there was little attention paid to the specific 


\section{Shared Communication in Building Mathematical Ideas: A Longitudinal Study}

colors, as students spoke of the solution in general terms. It is clear that Jeff was able to make sense of Michelle's explanation, as he completed her explanation. The doubling pattern could be said to constitute shared understanding.

Furthermore, by the time of this fourth-grade interview, students' representations had changed; they had moved on to diagrams, rather than concrete models of towers, to facilitate their organizations and develop their justifications. Their use of justification by cases and justification by contradiction, as well as their use of symbols to express patterns, shows their growing use of the mathematical register in expressing their understandings of the mathematical structure of the solutions to the towers problems.

Also note that at this point, students had been engaged in extensive investigation of the towers problems in various forms and from various points of view. Revisiting problems enabled students to adopt organizational strategies and ways of thinking used by other students, as for example when Jeff suggested a modification of Stephanie's organization by cases, and when Jeff participated in Michelle's explanation of the doubling pattern.

The next section presents another situation when Jeff adopted Stephanie's organizational strategy, this time for dealing with the "Pizza with Halves" problem.

\subsubsection{Fifth Grade: Pizza with Halves}

The students first encountered problems involving pizzas in fifth grade. In this first encounter, Jeff was in Group 2 with five other students, and the other four members of this cohort (Ankur, Brian, Michael, and Romina) were in Group 1 with two other students.

The Pizza with Halves problem (which is not isomorphic to the towers problem) is:

A local pizza shop has asked us to help them design a form to keep track of certain pizza sales. Their standard "plain" pizza contains cheese. On this cheese pizza, one or two toppings could be added to either half of the plain pizza or the whole pie. How many choices do customers have if they could choose from two different toppings (sausage and pepperoni) that could be placed on either the whole pizza or half of a cheese pizza? List all possibilities. Show your plan for determining these choices. Convince us that you have accounted for all possibilities and that there could be no more.

Group 1 used both drawings of pizzas and written words describing the pizzas. Some of Michael's drawings are shown in Figure 9 (from Uptegrove, 2007).

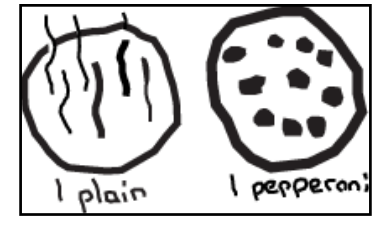

Figure 9. Representations of the plain and pepperoni pizzas 


\section{Shared Communication in Building Mathematical Ideas: A Longitudinal Study}

Group 2 also drew circles for pizzas, but they used letter codes for the toppings. Jeff's pizzas diagrams are shown in Figure 10.

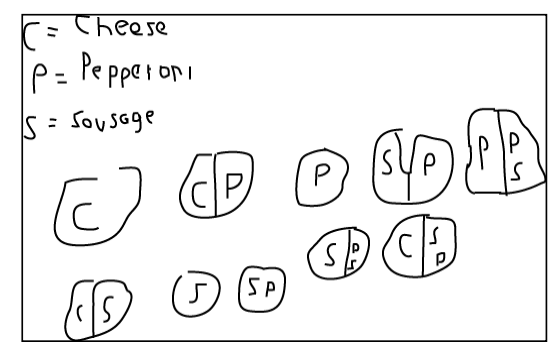

Figure 10. Jeff's representations of pizzas and half pizzas

While these drawings were perhaps realistic for the students, they focused on superficial features of the problems. Hence, the representations did not help the students to extract the important mathematical features of the problem, for example the idea that each topping could be either on the whole pizza, on half of the pizza, or not on the pizza at all. Further, although the researchers emphasized that the cheese pizza was the "no-topping" pizza, there remained confusion about whether or not to consider cheese as a separate topping. As reported by Bellisio (1999), students sometimes created two codes for the same one-topping pizza; for example, they used codes $\mathrm{S}$ (meaning sausage) and CS (meaning cheese/sausage). The fact that some students called the no-topping pizza "cheese" and others called it "plain" added to the confusion. Moreover, the code for pepperoni and the code for plain were often identical $(\boldsymbol{p})$ or similar $(\boldsymbol{p}$ or $\boldsymbol{p l})$, which was sometimes a source of confusion. These representations could not be considered to demonstrate attention to precision.

In spite of the variety of representations, the students worked together and through discussion came to a shared understanding of their various notations and organizational procedures. In the following excerpt, Stephanie expressed her disagreement with another student's approach, which was based on selecting one topping - for example sausage and building all possible pizzas that contained sausage, and then moving on to the next topping. Then she explained her alternate organizational strategy - that of grouping pizzas according to the number of different toppings - and Jeff indicated that he understood what Stephanie was saying.

Stephanie: You don't base it on anything. You just show how many different combinations you can make with like two little things, three little things, four little things.... So you put the one topping here, all the ones with one topping on top [i.e. in the first row of the table]. And then the ones with two toppings, you put those in the second row, and the ones with three toppings, you put them in the third row.

Jeff: $\quad$ She's actually starting to make sense.

Soon after, Jeff decided to reorganize his list according to Stephanie's proposal: 


\section{Shared Communication in Building Mathematical Ideas: A Longitudinal Study}

Jeff: $\quad$ I'm going to make a new graph. What you do is make a list of what you have with one topping. Then you make a list of the different things you can make with two toppings. Then you make the list of things you can make with halves, and so forth.

Here Jeff built mathematical knowledge through communication, as described by Staats and Batteen (2010), by "listening and reacting to" (p. 45) Stephanie's idea. We see that Jeff (along with Stephanie) knew the importance of organization, a key aspect of attending to precision.

By the conclusion of the "pizza with halves" sessions, students agreed on a total of 10 pizzas. While they used different categories to organize their pizza choices, all students attempted a justification by cases, indicating again use of an accepted form of reasoning. However, the students' representations continued to tend toward realistic depiction of surface features.

The next section details their written organizational schemes for the Pizza with Halves problem.

\subsubsection{Fifth Grade: Students' Letters}

Students were asked to write letters to researchers who were not present during the problem-solving sessions and explain their solutions to the Pizza with Halves problem. Their writing shows how they used organizational strategies. Here is what Romina wrote:

This week your friends gave us a pizza problem. We had 2 toppings and plain, sausage, and pepperoni. First my group and I made 3 whole pizzas. They were cheese, pepperoni and sausage. Then we made a section of halfs. Our half pizzas we had half pepperoni half plain, half sausage half plain, and half sausage and half pepperoni. Then we had a mixed section which we had a whole mixed, half plain half mixed, half pepperoni and half mixed, and half sausage and half mixed. Our total is ten pizzas.

Other students used the same scheme as described by Romina, or a similar organization, but they also included pictures. Figure 11 shows Michael's pictures and organization by cases: whole, half and mixed. 


\section{Shared Communication in Building Mathematical Ideas: A Longitudinal Study}

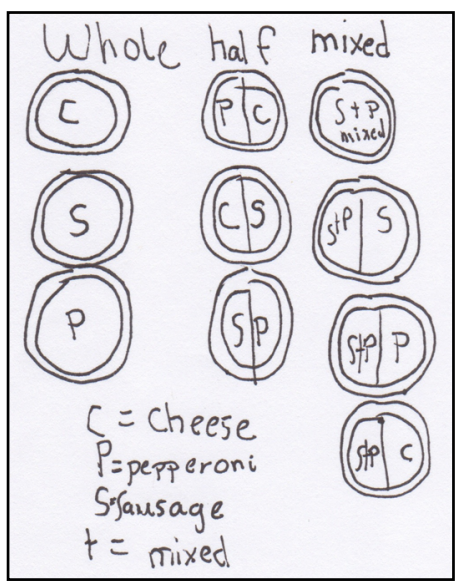

Figure 11. The pizza enumerations in Michael's letter

The students represented and communicated their ideas using words and diagrams. Moreover, their use of the mathematical register can be seen in their use of organized lists. This organization of pizza choices helped students because the cases were mutually exclusive (a key feature that was sometimes lacking in earlier organizations) and so they could deal with each case individually. As observed by Barwell (2013), their use of everyday language did not necessarily mean that they did not understand the mathematics. Their organization by cases provided a visual, rather than a written, justification of the correctness of their solution. Note, however, that the inclusion of the plain (cheese) pizza in the same category as the one-topping pizzas was mathematically inappropriate; it actually fit into the "no-topping" category. As is often the case, the empty set was difficult to express and classify.

\subsubsection{Fifth Grade: The Four-topping Pizza Problem}

One month after working on the Pizza with Halves problem, the entire class worked together on the regular four-topping pizza problem. In this session, they all used codes instead of drawings, an important step towards making use of the mathematical register. Also, the students now paid attention to general characteristics as compared with earlier strategies that focused on drawings. Within 10 minutes, the students found the 16 possibilities by organizing pizzas into groups, either according to the number of toppings or by making exhaustive lists for each topping in turn. Within each group, students carefully enumerated the number of pizzas, to make a convincing argument that accounted for all pizzas. In the excerpt below, Ankur showed how he found that there were six two-topping pizzas by creating subcases built around selecting the toppings in order:

- Subcase 1: an exhaustive list for peppers, by grouping them with sausage, mushroom, and pepperoni in turn.

- Subcase 2: an exhaustive list for sausage, grouping it with mushroom and pepperoni. 


\section{Shared Communication in Building Mathematical Ideas: A Longitudinal Study}

- Subcase 3: an exhaustive list for mushrooms, which consisted of the single case mushroom and pepperoni.

Researcher: Ankur, you wanna run through yours and see if we're agreeing there? These twos [two-topping pizzas]? How did you do it?

Ankur: $\quad$ I had a pattern.

Researcher: What was your pattern?

Ankur: I started with the first one and then mixed it with the second one so my first one was peppers and sausage, so I took peppers slash sausage. So I skipped, I started with the first one again, skipped the second one and then took the third one, P slash $\mathrm{M}$. Then I put peppers and then skipped the second and the third and I went with the fourth P slash PE. And then I started with the $\mathrm{S}$.

Researcher: You were sure you finished then? So then what did you do?

Ankur: $\quad$ Then I started with the second one with the $\mathrm{S}$ [the sausage] and mixed it with the mushrooms. And then sausage and pepperoni. Then I went down to the next one [mushrooms] and mushrooms and pepperoni.

Other classmates had similar conversations with researchers. Whole-class discussions revealed how, for these students, "meaning making occur[red] in social contexts" (Morgan, 2006, p. 220). The students made use of patterns, and they expressed their ideas through the use of codes and organized lists. These are all indicators of usage of the mathematical register. Further, in accordance with Barwell (2013), they used ordinary language (talking about pizza toppings) to express mathematical ideas.

The next section describes how, five years later, the students developed sophisticated mathematical notations, employed mathematical discourse, and used mathematical symbolism in representing their understanding of the towers and pizza problems and the relationship between those problems and the binomial expansion, Pascal's Triangle, and Pascal's Identity.

\subsection{Secondary School}

The five sessions described in this section took place after school, when the students were in high school. These sessions occurred about once every one to three months and they lasted an hour or more. In these five sessions, the students embarked on a further study of the pizza and towers problems, investigating how the problems could be related to each other, to the binomial expansion, and to Pascal's Triangle. The first four sessions took place in tenth grade; the last took place in grade 11. The sessions were:

- Michael's introduction of binary notation as a way to enumerate the answers to the pizza problems.

- The introduction to Pascal's Triangle and to the various notations used for combinations.

- A discussion with a visiting researcher in which the students used the towers problems to explain a particular instance of Pascal's Identity. 


\section{Shared Communication in Building Mathematical Ideas: A Longitudinal Study}

- The students' recognition of the isomorphic relationship between towers and pizza problems.

- The final session, in which the students put together all the pieces developed earlier.

This section discusses in detail the students' transition to full use of the mathematical register, with attention to the importance of revisiting problems. Often, several sessions were required for students to achieve a firm grasp of the mathematical concepts. In the final session discussed here, the students described Pascal's Identity in general terms by referring to pizza problems, and then they used standard mathematical notation and language in order to express this generalization mathematically.

\subsubsection{Tenth Grade: A New Representation}

During their first high school session in grade 10, the students revisited the three-, fourand five-topping pizza problems. Four of the students (Ankur, Brian, Jeff, and Romina) used a numerical code; for example, they represented the four-topping case by the numbers $1,2,3$, and 4 . This system was amenable to generalization for pizzas with varying numbers of toppings. It also represented a move toward recognizing the important features of the problem - number of toppings - as opposed to the surface features - what the actual toppings were. However, this organizational system had no way to represent the empty set: plain pizza; therefore, their answers for the three- and four-topping pizza questions were 7 and 15, respectively, "plus the plain." In addition, when it came to the five-topping pizza problem, their list yielded only 30 pizzas (again, "plus the plain"). The missing pizza was one of the three-topping pizzas, because the students had some trouble organizing the three-topping list. Note also that with the plain pizza outside this representational system, the doubling pattern was not so noticeable.

Michael created a different representation, using binary numbers (Muter, 1999; Uptegrove, 2005). This representation was flexible and generalizable. It also provided an easy way to represent the plain pizza. Further, it enabled Michael to demonstrate convincingly that the answer to the five-topping pizza problem is 32 . In fact, with this system, the students determined that the answer to the $n$-topping pizza problem is $2^{n}$.

Michael used the binary numbers 0 and 1 in a table with columns that represented topping choices. Figure 12 shows a portion of a table using Michael's notation for the case where there are four toppings available; column headers $\mathrm{O}, \mathrm{M}, \mathrm{P}$, and $\mathrm{S}$ represented topping choices onion, mushroom, pepperoni, and sausage. The numbers above the letters $(8,4,2$, and 1$)$ represented the place value of the digit 1 in that column. Notice that in each column, Michael placed either a 0 to indicate that the topping was not on the pizza or a 1 to indicate that the topping was on the pizza. With this scheme, any $n$-digit binary number corresponds to one particular pizza when there are $n$ toppings available. For example, in the four topping case, a plain pizza is represented by 0000 (this is the representation that the other system lacked), and one of the one-topping pizzas (pepperoni, for example) is represented by 0010 . 


\section{Shared Communication in Building Mathematical Ideas: A Longitudinal Study}

\begin{tabular}{|ccccl|}
\hline $\mathbf{8}$ & $\mathbf{4}$ & $\mathbf{2}$ & $\mathbf{1}$ & \\
$\mathbf{0}$ & $\mathbf{M}$ & $\mathbf{P}$ & $\mathbf{S}$ & \\
1 & 0 & 0 & 0 & $\leftarrow$ onion pizza \\
0 & 1 & 0 & 0 & $\leftarrow$ mushroom pizza \\
\hline
\end{tabular}

Figure 12. Michael's table linking topping codes and binary notation (annotation added) The following dialog shows that Jeff understood Michael's notation.

Researcher: What's the difference between 1000 and 0100 ?

Jeff: Well, that would be like - that would be the difference between an onion pizza and like a pepperoni pizza. ...

Michael: $\quad$ Every time you see a 1 in there, ... that pizza has an onion in it.

Jeff: $\quad$ In the first column. ...

Michael: $\quad$ Sausage, OK? Every time you see a 1 there [in the O column], you know that pizza has onions. Every time you see a 1 in this, in this place right there [the M column] you know it has mush, uh, mushrooms. And a 1 in this place [the P column], you know it has a pepper- no, pepperoni. And a one in this [the $\mathrm{S}$ column] is a sausage. That's what each of those 1's mean.

The exchange among the researcher, Jeff, and Michael is an example of students making meaning "in social contexts" (Morgan, 2006). Jeff took up Michael's ideas as shared understanding by "listening and reacting to" Michael's ideas (Staats \& Batteen, 2010, p. 45). In addition, the recognition of the utility of binary notation was an important milestone in the students' developing use of the mathematical register.

A week later, the group resumed the discussion of the pizza problem, in particular the meaning of the 2 in the solution $2^{n}$ (the number of possible pizzas where there are $n$ toppings to choose from). After about a half hour of discussion, Romina stated that the 2 stood for the fact that there are two choices in binary notation and in the placement of toppings: 0 (topping not present) and 1 (topping present); the others agreed.

The students went on to try to figure out how pizzas problems and towers problems might be related. They focused on relating number of pizza topping choices to number of colors of Unifix cubes. Believing that a three-topping pizza problem required a towers problem with three colors of Unifix cubes, Michael stated that binary notation would work only for $n=2$ (i.e. the isomorphism between the two-tall towers problem and the pizza problem with two topping choices). Hence, Michael and the others correctly described the isomorphism in a particular case $(n=2)$, but they did not generalize this finding.

Figure 13 shows Michael's table of solutions for the two-topping pizza problem and the two-tall towers problem. The column headers 1 and 2 represent the two pizza topping choices and the position of the cube of the tower. In each column, 1 represents "topping present" or "blue cube" and 0 represents "topping not present" or "red cube." 


\section{Shared Communication in Building Mathematical Ideas: A Longitudinal Study}

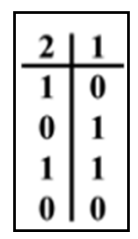

Figure 13. Michael's listing of two-tall towers and two-topping pizzas

The use of binary numbers gave Michael and his group a common language with which to communicate mathematically; it also provided the means to extract the important feature of the pizza problems - the binary choices - and allow the distracting surface features - particular pizza toppings - to recede into the background. However, the realization of the fact that only two colors of cubes were needed to map towers problems to pizza problems did not take place until a few months later.

The binary notation, having shown its power and potential for generalization, supplanted earlier notations and became the notation of choice for these students in many of their subsequent investigations. In addition, although the mistaken idea that the $n$-topping pizza problem must map to towers with $n$ choices for colors endured for some time, the students eventually, through further investigation and discussion, determined the correct isomorphic relationship: The number of available pizza toppings maps to the height of the tower and specific positions in the tower map to specific pizza toppings, with one color cube indicating "topping present" and the other indicating "topping not present." This again demonstrates the importance for learners of revisiting earlier explorations.

\subsubsection{Tenth Grade: Introduction to Combinations}

At a meeting about one month after Michael introduced the binary representation, the group worked on a question about the five-tall towers problem: When building towers from red and yellow cubes, how many five-tall towers are there with exactly two red cubes?

Using binary notation, with 1 representing red cubes and 0 representing yellow cubes, Ankur and Michael solved the problem in about two minutes. They started by listing towers according to the proximity of the two red cubes. After they created the first four entries in their list in which the two red cubes are next to each other, their organization was less systematic. During their explanation to the researcher, however, they moved to a more systematic approach. They fixed the color of the topmost cube as red and moved the second red cube through the other four possible positions. Then they fixed the topmost cube as blue and listed all possible towers with the first red cube in the second position and the second red cube moving through the other three possible positions, and so on. This list is shown in Figure 14. This illustrates how, through discourse, the students refined their work to provide a clearer and more systematic justification. It provides, also, an example of student usage of the mathematical register; this represents the mathematical structure but omits an unimportant surface feature: the colors of the cubes. 


\section{Shared Communication in Building Mathematical Ideas: A Longitudinal Study}

\begin{tabular}{llllllllll|}
\hline 1 & 1 & 1 & 1 & 0 & 0 & 0 & 0 & 0 & 0 \\
1 & 0 & 0 & 0 & 1 & 1 & 1 & 0 & 0 & 0 \\
0 & 1 & 0 & 0 & 1 & 0 & 0 & 1 & 1 & 0 \\
0 & 0 & 1 & 0 & 0 & 1 & 0 & 1 & 0 & 1 \\
0 & 0 & 0 & 1 & 0 & 0 & 1 & 0 & 1 & 1 \\
\hline
\end{tabular}

Figure 14. Ankur and Michael's diagram of five-tall towers with two red cubes

The researcher took this opportunity to provide some explicit context for the towers problems. After following up by asking how many towers had exactly zero, one, three, four, and five cubes, she showed the students how the answers to all these questions can be found in the fifth row of Pascal's Triangle. In other words, the numbers 15101051 gave, respectively, the number of five-tall towers with exactly $0,1,2,3,4$, and 5 blue cubes. She stated that asking how many five-tall towers have exactly two red cubes is the same as asking how many combinations there are when selecting two of five objects. The researcher then wrote the expansion of $(a+b)$ to powers 0 through 3 (Figure 15) and asked the students to think about the relationship between the binomial expansion and Pascal's Triangle.

$$
\begin{aligned}
& (a+b)^{0}=1 \\
& (a+b)^{1}=1 a+1 b \\
& (a+b)^{2}=1 a^{2}+2 a b+1 b^{2} \\
& (a+b)^{3}=1 a^{3}+3 a^{2} b+3 a b^{2}+1 b^{3}
\end{aligned}
$$

Figure 15. Researcher's listing of the binomial expansion

The researcher drew rows 0 through 5 of Pascal's Triangle and asked the students to make concrete the numbers in Pascal's Triangle, by thinking about them in a "very real way" (linking them to towers problems).

Researcher: ... when you first came in here today, you produced that number ten. [She refers to the first 10 in row 5 of Pascal's Triangle - 1510105 1.] Right?

Ankur: $\quad$ Yes.

Researcher: And what problem were you solving?

Ankur: $\quad$ Two were red and three something else. ... Three of another color.

Researcher: OK. So you can think of that ten in a very real way, if you want to, right?

Ankur: Yeah.

Researcher: Can you think of those other numbers in a real way? Does that help?

Ankur: $\quad$ The 1 is, in 14641 , the 1 represents all red. The other 1 represents all yellow I guess, and the 4 is probably-

Brian: $\quad$ Mixed.

Researcher: All red and all yellow for what? 


\section{Shared Communication in Building Mathematical Ideas: A Longitudinal Study}

Ankur: $\quad$ Of four high.

Here Ankur took the lead in making sense of Pascal's Triangle by following the pattern established by the researcher with row 5 and applying it to row 4 . Here is another example of a student making meaning through discourse. Ankur took up the researcher's statements as shared understanding by "listening to and reacting to" her ideas (Staats \& Batteen, 2010). In addition, they used the mathematical register: they used everyday language (colors of cubes in towers) to talk about mathematical ideas (the meaning of the numbers in Pascal's Triangle).

\subsubsection{Tenth Grade: Using Towers to Explain Pascal's Identity}

A month later, three members of the group (Ankur, Jeff, and Romina) met with a visiting mathematician, along with the primary researcher. In the process of explaining their recent investigations to him, they showed how individual instances of Pascal's Identity can be explained by the physical operation of building new towers through adding cubes to existing towers.

The students began by telling the visitor that the binomial expansion, the solutions to pizza problems, and the solutions to towers problems were related, although they could not explicitly describe the relationship. Recalling their earlier discussions, they maintained that the number of available pizza toppings is related to the number of color choices for building towers: They told the visitor that a five-topping pizza problem is somehow like a five-color towers problem; as was the case earlier, they were not able to explicitly describe the relationship.

In order to help the students recall (and possibly build on) their work from the previous month, the researcher returned to the discussion. She wrote out the expansion of $(a+b)$ and asked an explicit question: What are the relationships, if any, among $(a+b)^{5}$, the fivetall towers problem, and the five-topping pizza problem? The following dialog shows how the students answered that question.

Researcher: What are the $a$ 's and the $b$ 's here?

Romina: Colors....

Ankur: $\quad a$ is red and $b$ is blue.

Romina: $\quad b$ is blue.

Ankur: That's [red-blue tower] $a b$. So $b a$ would be a blue-red.

Researcher: So how, if you have them in front of you, how would they look different?

Ankur: $\quad$ Red and blue $[a b]$, red's on top.

Jeff: $\quad$ Red's on top.

Ankur: And blue's on the bottom. Blue's on top and red's on the bottom $[b a]$.

Note that each of the students built on statements of the others in the process of creating shared meaning through discourse. All were using the mathematical register in the sense of using the language of towers to make sense of the mathematics of Pascal's Triangle. 


\section{Shared Communication in Building Mathematical Ideas: A Longitudinal Study}

Next, the students were asked to work out the relationship between pizzas and Pascal's Triangle, with the researcher and the visitor having left the room. Ankur began by describing how row 6 of Pascal's Triangle is represented by six-tall towers built from red and blue cubes. Then Jeff directed the group's attention back to the question about pizzas. All three students participated in the discourse about the relationship between pizzas and the remaining numbers in row 6 . Notice that, a short time earlier, they had claimed that in order to relate a five-topping pizza problem to a towers problem, one needed five colors of cubes; now, they described that relationship using only two colors of cubes.

Ankur: This [1] is no red [a tower with no red cubes].

Jeff: $\quad$ Yeah.

Ankur: $\quad$ So there's one with no red. There's six with one red.... There's 15 with two reds. Twenty with three reds. Six with five reds.

Jeff: $\quad$ And one with no-

Ankur: $\quad$ And one with no-

Romina: [She disagrees.] No.

Ankur: [He corrects himself.] No. Six reds.

Jeff: $\quad$ One with six reds. ... All right. Now. What does that have to do with pizza?

Ankur: Just relate the tower problem to the pizza problem.

Jeff: $\quad$ Well, we're saying that this [1] is a pizza with just plain.

Romina: Yeah. That'll be the plain pizza.

Jeff: $\quad$ Plain. This [6] is with all your six toppings.

Romina: [She corrects Jeff.] That's with one topping.

Ankur: You can't exactly relate these numbers to the pizza problem.

Jeff: $\quad$ Well, we'll try really quick.

Romina: Yeah. You can. 'Cause this [1] is plain, just plain pizza.

Ankur: And what will the other 1 represent?

Romina: With everything on it.

Ankur: OK.

Jeff: $\quad$ So this is plain.

Ankur: OK. Six with-

Jeff: With one of each. Fifteen is with-

Romina: Two toppings.

Jeff: Just two toppings out of your six. Twenty is with three toppings. Fifteen is with the four toppings. Six is with the five toppings.

Romina: Five toppings.

Jeff: $\quad$ And the other one is-

Romina: And the one is with all of them.

Jeff: Like the supreme.

Note that not all initial statements made by the students were correct. For example, Jeff and Ankur both started to say "no reds" when Romina corrected them to "six reds." Then, when Ankur claimed that the towers problem could not be related to pizzas, Jeff 


\section{Shared Communication in Building Mathematical Ideas: A Longitudinal Study}

suggested that they could try, and Romina stated flatly that it could be done. She convinced Ankur of the possibility by providing the description of the pizzas related to the two 1's in row 6: the first 1 represents the plain pizza and the last 1 represents the pizza with all the toppings. Finally, Jeff at first indicated that the 6 meant all six toppings, but Romina corrected this, saying that it represented the pizzas with one topping each. Their shared understanding grew as they participated in discourse about the problems and their relationship to each other. Their use of the mathematical register included use of everyday language (descriptions of pizzas) to make sense of the mathematics of Pascal's Triangle. Figure 16 (from Uptegrove, 2005) is a diagram of how they related pizzas to Pascal's Triangle.

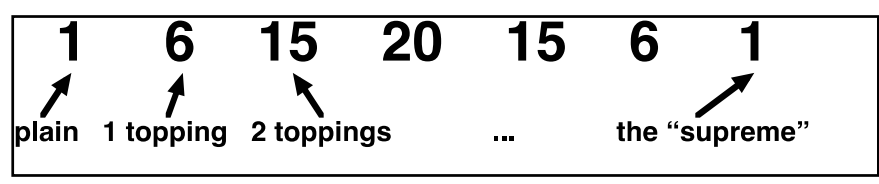

Figure 16. The relationship between pizzas and row 6 of Pascal's Triangle

At the end of the session, the group returned to the towers representation in explaining a specific instance of Pascal's Identity (how to build row 6 from row 5). The visitor asked them to explain how the two 10 's in row 5 combine to make the 20 in row 6 . The students explained that the first 10 counted the ten five-tall towers that have exactly two red cubes, and the second 10 counted the ten five-tall towers that have exactly three red cubes. So, they explained, one would place a red cube on top of the first ten towers and a blue cube on top of the other ten towers. Figure 17 (from Uptegrove, 2005) illustrates their explanation.

Visitor: What are those tens counting? And what do the, what does the 20 count?

Jeff: $\quad$ The tens show-

Ankur: The tens show two of one color.

Romina: And three of another.

Jeff: $\quad$ and the other one's three of-

Ankur: $\quad$-one color and two of another color.... That's why it's ten and ten. But then you, at the top of each one, you can put either-

Jeff: $\quad$ Yeah. You could either put a red or like blue....

Visitor: The first ten in that row of five high has two reds and three blues? We're counting reds?

Ankur: Yes.

Visitor: And the second ten has-

Ankur: $\quad$ Three reds and-

Visitor: -three reds and two blues. Now coming down here, the 20 is supposed to count the ones that have three of each.

Ankur: Three red. Three reds and three blues.

Jeff: $\quad$ Right.

Visitor: So how do the two tens add to give the 20? 


\section{Shared Communication in Building Mathematical Ideas: A Longitudinal Study}

Ankur: Because in these ten, where there's three reds and two blues, you want to make it three reds and three blues. So you put a blue on top of each one.

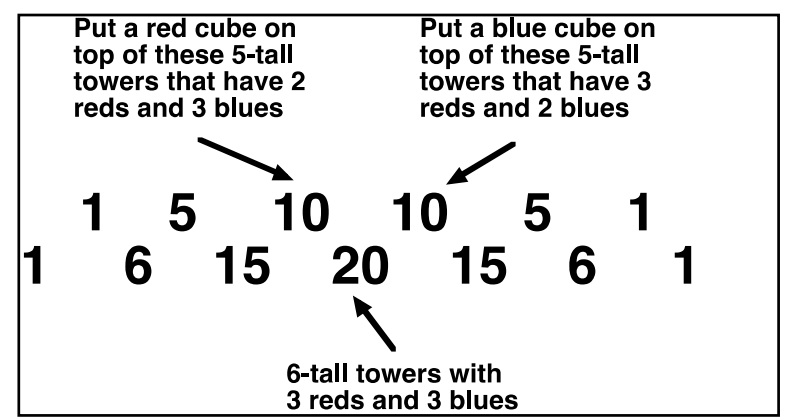

Figure 17. Using towers to represent Pascal's Identity

In discourse with the visiting mathematician, the students used the towers problem in order to make sense of a particular instantiation of Pascal's Identity. Here is an example of these students "being apprenticed into particular ways of doing mathematics in particular discursive contexts" as described by Schleppegrell (2007, p. 74).

In a later session, they showed that they were prepared to generalize this example, first in terms of towers, and then in terms of the mathematical register, generating their own versions of the two equations for Pascal's Identity given in Section 3.2.

\subsubsection{Tenth Grade: The Isomorphism Between Towers and Pizzas}

A month after the discussion with the visiting mathematician, Michael rejoined Ankur, Jeff, and Romina for a further discussion of the relationship between the towers and pizzas problems. At first, when asked to explain a particular instance of Pascal's Identity (how the first two terms in row 3 - the 13 of 1331 - can be added to give the first 4 in row 4), Jeff and Romina were unable to reproduce the concept discussed in the previous session; in other words, they did not recall how to place cubes on three-tall towers in order to generate four-tall towers. Michael and Ankur provided the answer as shown in the dialog below. Refer to Figure 18 for a diagram of their work.

Michael: ... each one of these four blocks [towers] is going to have something added to them to equal the same thing.

Ankur: Yeah.

Michael: These blocks [towers] are going to have, they're going to have a white block added to them. [Michael indicates the three 3-tall towers with one blue cube.]

Ankur: They're going to have a $b$ added to them.

Michael: And this one's [the all-white tower] going to have a, a blue added to it.

Ankur: $\quad$ An $a$ added to it. 


\section{Shared Communication in Building Mathematical Ideas: A Longitudinal Study}

Michael: And they're going to equal the same thing. That's why you're going to have the four.

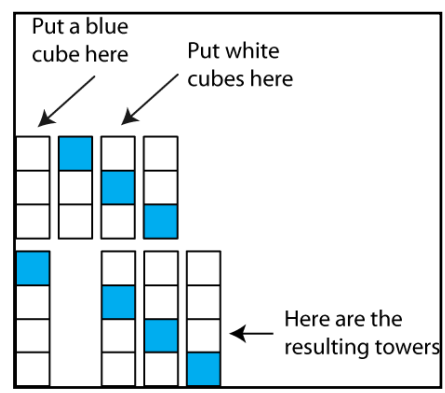

Figure 18. Michael and Ankur illustrate $1+3=4$ by adding cubes to towers

Note that Michael's mathematical language lacked some attention to precision: presumably he meant that the resulting four-tall towers were part of the same group, but the language "equal the same thing" did not make this explicit. Note also that Ankur made reference to another isomorphism: that the numbers in Pascal's Triangle are related to the coefficients of the binomial expansion of $(a+b)^{n}$. Ankur's mathematical language also lacked precision. It is likely that he meant that placing another white cube on a tower is equivalent to multiplying a term in the expansion of $(a+b)^{n}$ by $b$ (adding $b$ as a factor) and placing another blue cube on a tower is equivalent to multiplying a term in the expansion of $(a+b)^{n}$ by $a$ (adding an $a$ as a factor). However, he spoke merely about have "a $b$ added" or "an $a$ added."

In spite of the somewhat imprecise language, Ankur and Michael's process that could be generalized. Although the context involved moving from three-tall towers to four-tall towers, the procedures were general ones that could be applied to any two rows in Pascal's Triangle. Recall the middle-school work described earlier in which Michelle indicated that the number of towers doubles as the height increases by 1 . Here we observe the students' additional insights as they explored structural representations among representations: that the numbers are related to the binomial expansion, they can be identified in Pascal's Triangle, and they can be used to explain instances of Pascal's Identity. We see usage of the standard mathematical register in the students' reference to the binomial expansion and in their reference to Pascal's Identity.

Although the students recognized that the meaning of the numbers in Pascal's Triangle might be related both to the outcomes of categories from towers and pizza problems, they had not yet described an exact relationship, i.e., they had not mapped outcomes for individual towers to outcomes for individual pizzas. As this session continued, they provided this mapping. As can be seen in the transcript below, Ankur and the others at first did not understand how the colors of towers could be mapped to pizza toppings. Michael provided the correct explanation, one that the group accepted and built on together.

Ankur: $\quad$... Don't look at the colors. 


\section{Shared Communication in Building Mathematical Ideas: A Longitudinal Study}

Michael: No. No. No.

Ankur: $\quad$... But the colors don't specifically represent anything.

Romina: Yeah.

Michael: Yes. It does.

Ankur: $\quad$ No, it don't.

Michael: Topping. [Michael points to the blue cube.] Or no topping. [Michael points to the white cube]. Just say like that. And if you look at it like this, you know.

Ankur: $\quad$ So all of the whites are no topping?

Michael: Yeah. [Michael takes the all-white tower.] Then this is a plain pizza with a choice. If you had a choice of three toppings.

Jeff: All right.

Ankur: OK.

Romina: OK.

Michael: This [the blue-white-blue tower] would be a pizza-

Romina: Oh. With the one. Ooh.

Michael: -with two different toppings, without the other, third topping.

Ankur: $\quad$ OK. ... All right. All right. so that's [blue-blue tower] two toppings.

Romina: Yeah.

Jeff: $\quad$ Yeah. All right. So.

Michael: That's [white-white tower] ... a choice of two, but you want it plain.

Ankur: You have a choice of two toppings.

Jeff: $\quad$ Yeah, so this is, this [blue-blue tower] is choice of two using two.

This [blue-white tower] is choice of two using one.

Ankur: $\quad$ Two using one.

Jeff: $\quad$ This [white-blue tower] is choice of two using the other one.

Ankur: That's using the other one. And that's [white-white tower] using nothing.

Figure 19 illustrates their discussion.

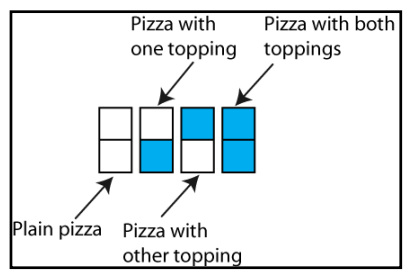

Figure 19. An isomorphism between pizzas and towers

At this point, having discussed examples of the exact relationship between outcomes of individual pizzas and towers, the students set the stage for using the "language, visual images and mathematical symbolism" (O'Halloran, 2005, p. 11) of the mathematical register in order to generalize their findings. 


\section{Shared Communication in Building Mathematical Ideas: A Longitudinal Study}

\subsubsection{Pascal's Identity and the Mathematical Register}

About a year after the session described in the previous section, the students met for an extended evening session lasting several hours. By the end of this session, referred to as Night Session, they had written Pascal's Identity in standard notation and provided a sound explanation of its meaning (Uptegrove, 2005). They did this by looking at general forms of solutions to the towers and pizza problems, referring back to how they had previously explained specific instances of Pascal's Identity in terms of towers and pizzas, and also making use of Michael's binary notation. The episodes discussed here show the progression from a discussion of the meaning of specific numbers in Pascal's Triangle through an explanation of specific instances of Pascal's Identity to the final generalization.

Four of the students (Ankur, Jeff, Michael, and Romina) participated. In the first episode, Michael recalled his previous work by noting that row 3 of Pascal's Triangle can be thought of as the number of possible pizzas when selecting from three toppings. First Michael recalled the binary notation that describes specific pizzas. A portion of the discussion follows.

Michael: Let's go to this one. ... [Michael indicates row 3: 1333 1.]

Jeff: $\quad$ That would be $a$ plus $b$ to the third.

Michael: All right, let's say you have like, here's a number, all right? [Michael writes 000 .] Zero means no toppings. ... One would be a topping. So first category is everything with no toppings. [Michael points to the first 1 in row 3.] ... that's your number for that one. [Michael points to 000 .] That's like, like binary numbers or something. Next would be- [Michael writes 001, 010, then 101.] There's all the, the ones that have one topping.

Jeff: $\quad$ Right, you got to write that 0 at the end. You messed up. Last one should be 100, not 101 .

Michael: I knew that. [Michael changes 101 to 100.]

Note that Jeff brought in the relationship to the binary expansion (" $a$ plus $b$ to the third") and then corrected Michael's mistake in writing one of the binary numbers, showing that he shared Michael's understanding of the representation and the isomorphism.

Michael described how those pizza choices could be used to build the pizza choices in row 4 of Pascal's Triangle (when there are four available toppings). He specifically described what happens to the three pizzas in row 3 that represent the one-topping pizza possibilities (the first 3 in 133 1):

So all these threes would either move up a step onto the next category and, uh, have two toppings. [Michael points to the 6 in row 4.] Or they might stay behind and still only have one [topping] ... [Michael points to the 4 in row 4.]

Figure 20 illustrates Michael's explanation, as he referred to specific entries in Pascal's Triangle. Notice that he gave a general procedure for generating entries. Also notice that 


\section{Shared Communication in Building Mathematical Ideas: A Longitudinal Study}

Michael did not name specific pizza toppings. Michael was expressing a general rule in terms of specific cases.

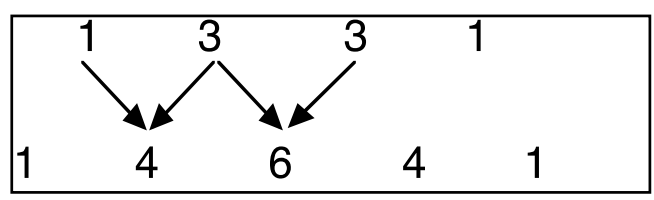

Figure 20. Specific instances of Pascal's Identity

Next, the researcher asked the students to work in what they called "choose" notation. Drawing row 3 from Pascal's triangle, she asked them to illustrate the addition rule (in particular $3+3=6$ ) using that notation. The group responded by creating the diagram shown in Figure 21. This diagram can be expressed as $\left(\begin{array}{l}3 \\ 1\end{array}\right)+\left(\begin{array}{l}3 \\ 2\end{array}\right)=\left(\begin{array}{l}4 \\ 2\end{array}\right)$. Michael explained in terms of pizzas: "this guy [the first addend] gets another topping, I guess, so he would be a 2 . And this guy [the second addend] doesn't, so it stays 2." Like Jeff and Romina in fourth grade (who spoke of pairs of towers as "married couples"), Michael employed personification and everyday language in the service of mathematical discussion. The reference to " 2 " indicates the 2 in $\left(\begin{array}{l}4 \\ 2\end{array}\right)$, an indication that Michael was making use of the pattern in the equation, a pattern that Ankur also referenced in the following episode. Note that at this point, even though they were dealing with a concrete problem (pizzas) and a specific row of Pascal's Triangle (row 3) the students spoke in general terms. The concept of adding a topping to the addend on the left and not adding a topping to the addend on the right applies to any entries in any row of Pascal's Triangle, not just the first two entries in the third row. We see here that the students were successfully using standard combinatorial notation for a particular instance of Pascal's Identity, and they spoke about the particular entries in general terms. They were getting ready for the next step: writing Pascal's Identity in general form.

$$
\begin{array}{|c|}
\hline\left(\begin{array}{l}
3 \\
0
\end{array}\right)\left(\begin{array}{l}
3 \\
1
\end{array}\right)\left(\begin{array}{l}
3 \\
2
\end{array}\right)\left(\begin{array}{l}
3 \\
3
\end{array}\right) \\
\left(\begin{array}{l}
4 \\
0
\end{array}\right)\left(\begin{array}{l}
4 \\
1
\end{array}\right)\left(\begin{array}{l}
4 \\
2
\end{array}\right)\left(\begin{array}{l}
4 \\
3
\end{array}\right)\left(\begin{array}{l}
4 \\
4
\end{array}\right) \\
\hline
\end{array}
$$

Figure 21. An instance of Pascal's Identity in "choose" notation

The researcher asked the students to choose a generalized row of Pascal's Triangle and to show how the addition rule would look for that row. With coaching from the others, Jeff wrote row $N$ as shown in Figure 22, and then he followed up with some examples of the 


\section{Shared Communication in Building Mathematical Ideas: A Longitudinal Study}

previous row, row $N-1$. Then, directed by Ankur and Michael, he wrote a single entry for row $\mathrm{N}+1$ and used arrows to indicate how the numbers were added.

$\left(\begin{array}{c}N-1 \\ 0\end{array}\right)$
$\left(\begin{array}{c}N \\ 0\end{array}\right) \cdots\left(\begin{array}{c}N \\ X \\ X-2\end{array}\right)\left(\begin{array}{c}N \\ X-1\end{array}\right)\left(\begin{array}{c}N \\ X\end{array}\right)\left(\begin{array}{c}N \\ X+1\end{array}\right)\left(\begin{array}{c}N-1 \\ N-1\end{array}\right) \ldots\left(\begin{array}{c}N \\ X+2\end{array}\right)$
$\left.\downarrow \begin{array}{l}\downarrow \\ N\end{array}\right)$
$\left(\begin{array}{l}N+1 \\ X+1\end{array}\right)$

Figure 22. General rows of Pascal's Triangle with instance of Pascal's Identity

Finally, again with helpful input from the others, Jeff wrote the resulting equation, shown in Figure 23. This is mathematically equivalent to the standard textbook equation in Figure 3.

$$
\left(\begin{array}{l}
N \\
X
\end{array}\right)+\left(\begin{array}{c}
N \\
X+1
\end{array}\right)=\left(\begin{array}{l}
N+1 \\
X+1
\end{array}\right)
$$

Figure 23. Students' version of Pascal's Identity

The availability of the standard notation had freed the students from the necessity of working with specific numbers. Just as the use of the binary notation had freed the students from the necessity of referring to specific toppings, the use of the standard notation permitted the students to talk about and write about general entries in Pascal's Triangle rather than specific pizzas with specific numbers of toppings.

Following is a excerpt of the discussion when the group produced the final equation (after Brian had joined them).

Researcher: Can you write it as an equation? Just like you wrote three plus three equals six. ... Say it so Brian can follow it because he wasn't here for the earlier pizza discussion. ...

Jeff: $\quad$ What, what we're doing is the next line of the triangle. Remember how today in class the other triangle was one, two?

Brian: Yeah.

Jeff: $\quad$. . Say we're doing pizzas.

Brian: All right.

Romina: ... You know how we get the triangle and how we ... add those two together?

Brian: Yeah.

Jeff: $\quad$... We were explaining why you add.

Brian: All right, keep going. 


\section{Shared Communication in Building Mathematical Ideas: A Longitudinal Study}

Jeff: $\quad$... If it gets a topping, that's why it goes up to the X plus 1. [Jeff points to the first addend.] And since it doesn't get anything it'll stay the same. And in this one, it's staying the same, right? [Jeff points to the second addend and looks at Michael, who nods.] ... Make sense? Brian: $\quad$ Yes. It actually does.

Jeff: $\quad$ So, so that would be the general addition rule in this case.

The students thus represented their ideas by producing an equation in the mathematical symbolism of the mathematical register. It conformed to the "established mathematical symbolism" mentioned by Skemp (1987). It was understandable, precise, and general.

Also, note, that the students made use of O'Halloran's (2005) three components of the mathematical register:

1. Language, in their group discussions of their work. This included both mathematical language and everyday language, as when Jeff returned to the pizza problem in order to explain the general addition rule. Note that this can also be considered an example of what Barwell (2013) called learning to communicate mathematics appropriately: When explaining the mathematics to Brian, a peer who had missed the earlier mathematical discussion, Jeff found it appropriate to use a well-known specific problem of pizzas.

2. Visual images, in their depiction of Pascal's Triangle.

3. Mathematical symbolism, in their use of combinatorics notation to express Pascal's Identity.

\subsubsection{Factorial Notation}

Following the above episode, the students were asked to convert the combinatorics notation to factorial notation. They had learned about factorial notation in their regular math class, so converting from one form of the mathematics register to another was a matter of algebraic manipulation.

At first Michael wrote the equation shown in Figure 24, with help from Ankur and Jeff. When he got to the third term, he struggled with writing the denominator, and Ankur told him to copy the denominator from the previous term (the second addend). This was incorrect, and the mistake could have been due to the fact that the combinatorics notation is similar to fraction notation. The students might have assumed that because the bottom numbers in the combinatorics notation were the same, the denominators of the fractions would be the same as well. This might indicate that the students were less familiar with the factorial notation, especially when it was not anchored to specific meanings, such as towers or pizzas.

$$
\left(\frac{n !}{(n-x) ! x !}\right)+\left(\frac{n !}{(n-(x+1)) !(x+1) !}\right)=\frac{(n+1) !}{(n-(x+1)) !(x+1) !}
$$

Figure 24. Pascal's Identity (with algebraic error) 


\section{Shared Communication in Building Mathematical Ideas: A Longitudinal Study}

Jeff commented, "Do you know how intimidating this equation must be, if you just pick up a book and look at that?" This suggests that making sense of the standard register gave meaning to something that would otherwise have been intimidating.

After the students were asked to check the equation for mistakes and possibility of simplification, they produced a correct, slightly more simplified version of Pascal's Identity expressed with factorials, as shown in Figure 25.

$$
\left(\frac{n !}{(n-x) ! x !}\right)+\left(\frac{n !}{(n-(x+1)) !(x+1) !}\right)=\frac{(n+1) !}{(n-x) !(x+1) !}
$$

Figure 25. Pascal's Identity (simplified factorial form)

The equation in Figure 25 is equivalent to the textbook version of the equation shown in Figure 4. These final episodes show that these students developed a solid understanding of the meaning of the numbers in Pascal's Triangle and how they are joined in the equation called Pascal's Identity. The students demonstrated fluency in the use of the mathematical register by using mathematical language, visual diagrams, and the notations of combinatorics.

\section{Summary and Discussion}

In this work I traced the developing use of the mathematical register of a group of students over a period of nine years of their participation in a longitudinal study of students' mathematical reasoning. I showed how the need to justify their answers required the students to organize their ideas and to find ways to communicate them in a way that was understandable to others. Hence, from the beginning, they found a need for use of understandable terminology and precision in language. Their move from personal, idiosyncratic representations to shared, commonly accepted representations was a natural result of their working together. I then showed how the use of standard notation met the students' further need to generalize their findings. I also showed how these students were able to revert back to everyday language (talking about pizzas and towers) when appropriate to express their ideas; for example in discussing their recognition of the isomorphism between those two problems, linked by the common representation of Pascal's Triangle.

In the following sections, I summarize the answers to the research questions.

\subsection{Representations used by students}

In the earlier years, students' representations tended to focus on surface aspects of the problems. Students shared their ideas using everyday language and idiosyncratic descriptions (e.g. taking "couples" for a "stroll"), and they treated the pizza and towers problems as unrelated questions, requiring different strategies and different representations. In their middle school work, students' representations, such as codes for pizza toppings, often included mathematically irrelevant surface features. However, these 


\section{Shared Communication in Building Mathematical Ideas: A Longitudinal Study}

representations were now integrated with powerful organizational strategies and logical justifications for their arguments. In their high school problem solving, the students developed a common notation that allowed them to represent both the towers and pizza problems, helping them recognize their isomorphic relationship (i.e. the fact that the underlying mathematical structures for the solutions were the same), and they also discovered how those problems were related to the mathematics of binary notation, the binomial expansion, Pascal's Triangle, and Pascal's Identity.

\subsection{Students' move to use of mathematical register}

The students move to the use of the standard mathematical register was necessitated both by the increasingly abstract questions they encountered, questions that could not be answered fully by referring to instances of the pizza and towers problems, and by the need to describe and explain Pascal's Identity in general form. The standard notation gave them a tool for making general, concise, and mathematically understandable statements that encapsulated the mathematical structure of the two problems. The standard notation was also the means for them to describe the relationship know as Pascal's Identity. However, they still had everyday language at their disposal when they it was needed, for example, for purposes of explaining the meaning of Pascal's Identity from the perspective of building towers and adding toppings to pizzas.

\subsection{Areas for further discussion}

A question arises as to whether some of the students' progress in use of the mathematical register might be attributed to other factors, such as maturation. Other research suggests that when older students encounter the pizza and towers problems for the first time, they use the same strategies as the younger students - using manipulatives to build models, organizing towers by "opposites," and listing pizza toppings, for example (Glass, 2001; Brophy, 2013). Glass (2001) reported that community college students came to accept a classroom culture that defined and required convincing arguments, but this attitude is not something that they brought into the classroom. Brophy (2013), reporting on preservice math teachers in a junior-level college math class, indicated that these college students worked on the problems with an expectation that they would be required to generalize and justify their findings. A reasonable explanation is that previous experience as math majors had already introduced them to a classroom culture requiring proof and justification. In addition, third-year math majors can be expected to possess some fluency in the mathematical register.

\section{Pedagogical Implications}

Although this study was not primarily focused on pedagogy, there are pedagogical implications to the findings reported. This study has shown that it is not necessary or even desirable for teachers to discourage students from use of unconventional and highly personal representations in early investigations of mathematical problems. Rather, teachers can encourage the growth of students' use of the mathematical register by requesting convincing arguments and by helping students learn what makes a convincing argument. See for example, the discussion between Jeff and the researcher, and the whole 


\section{Shared Communication in Building Mathematical Ideas: A Longitudinal Study}

class discussion about towers with exactly one blue cube, both in Section 4.1.2. In these episodes, the researchers rephrased student comments in a way that demonstrated appropriate ways to defend their conclusions. Also note that in Section 4.1.3, we observe students who accepted the classroom culture of defending and explaining their answers and who were prepared to offer convincing justifications for their answers.

Additionally, by showing how students often needed to revisit problems in order to fully develop their understandings, this study has illustrated the process described by Pirie and Kieren (1994) as "folding back," i.e. returning to an earlier level of understanding in order to reconstruct and elaborate on earlier ideas that were perhaps not completely understood. This illustrates the importance of providing opportunities for students to revisit problems in order to build on earlier understandings. It suggests that it might not necessarily be reasonable to expect students to fully grasp important mathematical concepts the first time they are encountered.

\section{Conclusions}

This research provides an example of a cohort of students learning to use the standard mathematical register through long-term investigations in counting and combinatorics problems, thus showing that it is possible for students in high school and earlier grades to develop this facility. Furthermore, the use of earlier idiosyncratic personal representations by these students did not hinder their eventual adoption of the standard mathematical register. In fact, these earlier representations were subsumed into a more general and powerful representational system as the students discovered better organizational strategies and were introduced to the more powerful standard notation. This suggests that the early use of personal representations can be helpful when students are working to understand mathematical problems. Recognizing the limitations of these personal representations, as noted by Skemp (1987), can compel students to adopt the standard notation as a means to express their understanding. See also the case of Ariel (Sigley \& Wilkinson, 2015).

Additionally, the students in this study were still able to refer back to earlier investigations and ways of talking about the problems when they wanted to describe specific instances of more general rules. As Barwell (2013) noted, part of learning to communicate mathematically is learning to express mathematical knowledge in different ways for different situations. These students used technical terminology and symbols appropriately when necessary, and they also used everyday language when it was the appropriate medium of expression (for example, when explaining the mathematical symbols to a newly-arrived classmate).

In summary, this research suggests that students who build meaning first and then develop the symbolic vocabulary of the standard mathematical register can acquire a deep and durable understanding. In addition, building meaning first can give students an expanded mathematical vocabulary; not only can they express ideas using the standard mathematical terminology, but they can also use everyday language when necessary and appropriate. 


\section{Shared Communication in Building Mathematical Ideas: A Longitudinal Study}

\section{Acknowledgement}

Support for the longitudinal study was provided by National Science Foundation grants MDR-9053597 (directed by R. B. Davis and C. A. Maher) and REC-9814846 (directed by C. A. Maher). Opinions, findings, and conclusions are those of the author and they do not necessarily reflect the views of the funding agency.

\section{References}

Agnew, G., Mills, C., \& Maher, C. (2010). VMCAnalytic: Developing a collaborative video analysis tool for education faculty and practicing educators. In R. H. Sprague, Jr. (Ed.), Proceedings of the 43rd Annual Hawaii International Conference on System Sciences (HICCS-43): Abstracts and CD-ROM of Full Papers. IEEE Computer Society, Conference Publishing Services: Los Alamitos, CA.

Barwell, R. (2013). The academic and the everyday in mathematicians' talk: the case of the hyper-bagel. Language and Education, 27:3, 207-222.

Bellisio, C. (1999). A study of elementary students' ability to work with algebraic notation and variables. Unpublished doctoral dissertation, Rutgers University, NJ.

Brophy, A. (2013). Exploring and justifying ideas in an undergraduate mathematics course: A case study. Unpublished doctoral dissertation, Rutgers University, NJ.

Common Core State Standards. (2010). Common Core State Standards for Mathematics. Retrieved October 26, 2014 from http://www.corestandards.org/Math/

Cuoco, A. \& F. Curcio, F. (Eds.), (2001). The Roles of Representation in School Mathematics, 2001 Yearbook. Reston, VA: National Council of Teachers of Mathematics.

Davis, R., \& Maher, C (1997). How students think: The role of representations. In L. English, (Ed.), Mathematical Reasoning: Analogies, Metaphors and Images (pp. 93-115). Mahwah, NJ: Lawrence Erlbaum Associates.

Glass, B. (2001). Problem solving and justification with community college students. Unpublished doctoral dissertation, Rutgers, the State University of New Jersey, New Brunswick, NJ.

Goldin, G. (1998). Representational systems, learning, and problem solving in mathematics. The Journal of Mathematical Behavior, 17, 137-165.

Halliday, M. (1978). Language as social semiotic. London: Edward Arnold.

Hoffman, M. (2006). Signs. Educational Studies in Mathematics, 61, 279-291.

Lehrer, R., Schauble, L. Carpenter, S., \& Penner. D. (2000). The interrelated development of inscriptions and conceptual understanding. In P. Cobb, E. Yackel, 


\section{Shared Communication in Building Mathematical Ideas: A Longitudinal Study}

\& K. McClain (Eds.), Symbolizing and Communicating in Mathematics Classrooms (pp. 325-360). Mahwah, NJ: Lawrence Erlbaum Associates.

Maher, C. (2005). How students structure their own investigations and learn mathematics: Insights from a long-term study. The Journal of Mathematical Behavior, 19, 1-14.

Maher, C. (2010). The Longitudinal study. In C. Maher, A. Powell, \& E. Uptegrove (Eds.). Combinatorics and reasoning: Representing, Justifying and Building Isomorphisms (pp. 9-14). New York: Springer.

Maher, C., \& Martino, A. (1996). Young children invent methods of proof: The gang of four. In P. Nesher, L. Steffe, P. Cobb, B. Greer, \& G. Goldin (Eds.), Theories of mathematical learning (pp. 431-447). Lawrence Erlbaum Associates: Mahwah, NJ.

Maher, C., Landis, J., \& Palius, M. (2010). Teachers attending to students' reasoning: using videos as tools. Journal of mathematics education, 3(2), 1-24.

Maher, C., Powell, A., \& Uptegrove, E. (Eds.), (2010). Combinatorics and reasoning: Representing, justifying and building isomorphisms. New York: Springer Publishers.

Maher, C., Sran, M., \& Yankelewitz, D. (2010a). Towers: Schemes, strategies, and arguments. In C. Maher, A. Powell, \& E. Uptegrove (Eds.), Combinatorics and Reasoning: Representing, Justifying and Building Isomorphisms (pp. 27-43). New York: Springer.

Maher, C., Sran, M., \& Yankelewitz, D. (2010b). Making pizzas: Reasoning by cases and by recursion. In C. Maher, A. Powell, \& E. Uptegrove (Eds.), Combinatorics and Reasoning: Representing, Justifying and Building Isomorphisms (pp. 59-72). New York: Springer.

Martino, A., \& Maher, C. A. (1999). Teacher questioning to promote justification and generalization: What research practice has taught us. The Journal of Mathematical Behavior, 18, 53-78.

Morgan, C. (1998). Writing mathematically: The discourse of investigation. London: Palmer.

Morgan, C. (2006). What does social semiotics have to offer mathematics education? Educational Studies in Mathematics, 61, 219-245.

Moschkovich, J. (2008). I went by twos, he went by one: Multiple interpretations of inscriptions as resources for mathematical discussions. The Journal of the Learning Sciences 17(4), 551-587.

Muter, E. (1999). The Development of Student Ideas in Combinatorics and Proof: A SixYear Study. Unpublished doctoral dissertation, Rutgers University, NJ. 


\section{Shared Communication in Building Mathematical Ideas: A Longitudinal Study}

Muter, E., \& Maher, C. (1999). Recognizing isomorphism and building proof: Revisiting earlier ideas. In Proceedings of the Twentieth Annual Meeting of the North American Chapter of the International Group for the Psychology of Mathematics Education (PME-NA 20) (Vol. 2, pp. 461-467). Raleigh, NC: North Carolina State University.

Muter, E., \& Uptegrove, E. (2010). Representations and connections. In C. Maher, A. Powell, \& E. Uptegrove (Eds.), Combinatorics and Reasoning: Representing, Justifying and Building Isomorphisms (pp. 105-120). New York: Springer.

National Council of Teachers of Mathematics (2000). Principles and Standards for School Mathematics. Reston, VA: National Council of Teachers of Mathematics.

O'Halloran, K. (2005). Mathematical discourse: Language, symbolism and visual images. New York: Continuum.

Pirie, S. \& Kieren, T. (1994). Growth in mathematical understanding: How can we characterize it and how can we represent it? Educational Studies in Mathematics, 26(2-3), 165-190.

Schleppegrell, M. (2007). The linguistic challenges of mathematics teaching and learning: A research review. In J. Moschkovich (Ed.), Language and Mathematics Education (pp. 73-112). Charlotte, NC: Information Age Publishing.

Sfard, A., (2000). Symbolizing mathematical reality into being - or how mathematical discourse and mathematical objects create each other. In P. Cobb, E. Yackel, \& K. McClain (Eds.), Symbolizing and Communicating in Mathematics Classrooms (pp. 37-98). New York: Routledge.

Sigley, R., \& Wilkinson, L. (2015). Ariel's Cycles of Problem Solving: An Adolescent Acquires the Mathematics Register. The Journal of Mathematical Behavior, this volume.

Skemp, R. (1987). The Psychology of Learning Mathematics. Hillsdale, NJ: Lawrence Erlbaum Associates.

Staats, S., \& Batteen, C. (2010). Linguistic indexicality in algebra discussions. The Journal of Mathematical Behavior, 29, 41-56.

Uptegrove, E. (2005). To symbols from meaning: Students' investigations in counting. Unpublished doctoral dissertation, Rutgers University: NJ.

Uptegrove, E. (2007). Making sense of standard notation. School Connections, 18(1), 3239.

Uptegrove, E. (2010). Representations and standard notation. In C. Maher, A. Powell, \& E. Uptegrove (Eds.), Combinatorics and reasoning: Representing, justifying and building isomorphisms (pp. 133-144). New York: Springer. 